\title{
O.S.P.
}

\section{Lorientation scolaire et professionnelle}

$35 / 2 \mid 2006$

Adolescences - 2

\section{B. Rogé \& H. Chabrol. Psychopathologie de l'enfant et de l'adolescent}

Paris : Belin

Lyda Lannegrand-Willems

\section{OpenEdition}

\section{Journals}

Édition électronique

URL : https://journals.openedition.org/osp/1135

DOI : $10.4000 /$ osp. 1135

ISSN : 2104-3795

Éditeur

Institut national d'étude du travail et d'orientation professionnelle (INETOP)

Édition imprimée

Date de publication : 15 juin 2006

Pagination : 298

ISSN : 0249-6739

Référence électronique

Lyda Lannegrand-Willems, « B. Rogé \& H. Chabrol. Psychopathologie de l'enfant et de l'adolescent », L'orientation scolaire et professionnelle [En ligne], 35/2 | 2006, mis en ligne le 28 septembre 2009,

consulté le 18 janvier 2022. URL : http://journals.openedition.org/osp/1135; DOI : https://doi.org/

10.4000/osp. 1135

Ce document a été généré automatiquement le 18 janvier 2022.

(c) Tous droits réservés 
B. Rogé \& H. Chabrol. Psychopathologie de l'enfant et de l'adolescent

Paris : Belin

Lyda Lannegrand-Willems 


\section{RÉFÉRENCE}

Paris : Belin

1 L'ouvrage de $\mathrm{B}$. Rogé et $\mathrm{H}$. Chabrol constitue une introduction à cette thématique (c'est un ouvrage abordable par un public très large - étudiants, professionnels et parents -) et une ouverture sur les psychopathologies de l'enfant. Une première partie aborde ici les psychopathologies rencontrées par les enfants et/ou les adolescents (troubles anxieux, dépressions, troubles déficitaires de l'attention - hyperactivité, troubles des conduites, troubles liés aux substances psychoactives, schizophrénies, autisme, déficience intellectuelle, troubles du langage et des apprentissages scolaires, troubles alimentaires, troubles du sommeil, énurésie-encoprésie), en spécifiant pour chacune d'elles les critères de diagnostic, les facteurs déterminants et un aperçu des traitements possibles. En fin de chaque présentation de troubles, des exercices sous forme de questions / réponses permettent au lecteur de faire le point sur les connaissances qu'il a pu acquérir au fil de la lecture. Une seconde partie de l'ouvrage, à travers la description et l'analyse de 15 cas cliniques, a pour objectif d'illustrer la plupart des psychopathologies de l'enfant et de l'adolescent définies dans la première partie.

2 Le souci pédagogique et la clarté de la présentation des différentes psychopathologies aussi bien dans les aspects descriptifs que dans les aspects illustratifs font de cet ouvrage une très bonne introduction aux questions soulevées par les psychopathologies de l'enfant et de l'adolescent. 